\title{
A Rare Case of Blast Effect by Lightening
}

Nitin S Barmate ${ }^{1 *}$, Nilesh K Tumram ${ }^{2}$, Raj Kumar Singh ${ }^{1}$ and Manish B Shrigiriwar ${ }^{3}$

${ }^{1}$ Forensic Medicine, Pt. JNM Medical College, Raipur, Chhattisgarh, India

${ }^{2}$ Forensic Medicine, Govt Medical College, Nagpur, Maharashtra, India

${ }^{3}$ Forensic Medicine, Shri VN Govt Medical College, Yavatmal, Maharashtra, India

\begin{abstract}
Lightning is one of the most potent and extravagant natural phenomena. Deaths related to the striking of lightning occurs in persons functioning in open space like farming, golfing, fishing, swimming, boating, camping, or hiking. Here we present a case of $45 \mathrm{yr}$ male who sustained lightening injuries in form of blast effect causing rupture of the tympanic membrane and mucosal and submucosal hemorrhage in the stomach and intestine. Such a phenomenon is very rare in lightening deaths and is not reported previously in literature to the best of our knowledge.
\end{abstract}

Keywords: Lightening; Blast effect; Ruptured tympanum; Submucosal haemorrhage; Stomach

\section{Introduction}

Lightning is one of the most powerful and spectacular natural phenomena. Deaths related to the striking of lightning occurs in persons functioning in open space like farming, golfing, fishing, swimming, boating, camping, or hiking. It is one of the second leading causes of death due natural calamity involving weather-related death after flooding [1].

Herein we report a rare case report with injuries by blast effect on the ear and gastrointestinal tract due to lightening which was not previously reported in literature to the best of our knowledge.

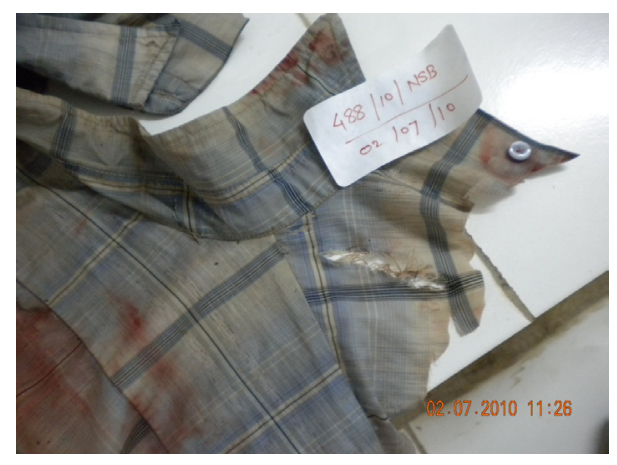

Figure 1: Scorching effect over shirt.

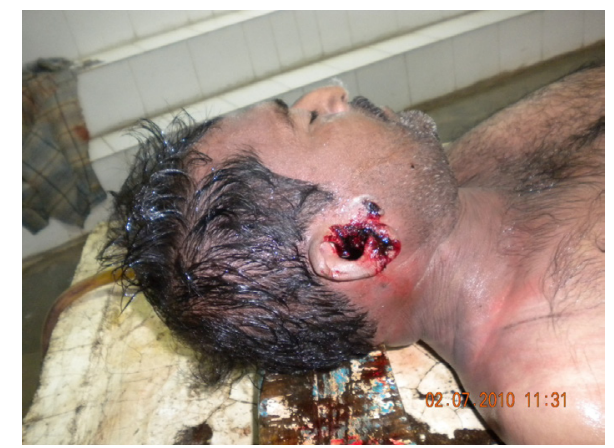

Figure 2: Oozing of blood through ears.

\section{Case}

\section{History}

In an early morning of the day of the incident a 45 years male was working along with his wife who was at some distance to him in the agriculture field. It was a rainy day in our region. Rain started along with lightening and air storm. In the same event, lightening stroked nearby the victim, which was witnessed by his wife. The victim was lying unconscious on the ground. Deceased was brought dead to our Apex Medical College.

\section{Autopsy finding}

On the same day of the incident the deceased was brought for medicolegal autopsy at our hospital. The victim was dressed with one shirt, and dhoti. The clothes were stained with mud particles and were wet with water. The shirt was torn anteriorly around the right shoulder region along with scorching due to lightening (Figure 1).

On external examination-The deceased was average built with well developed rigor mortis in the whole body. Postmortem lividity was seen over back and was fixed. There was oozing of blood from both ears (Figure 2). On otoscopic examination perforation of the tympanic membrane was observed. The epidermal burn wound was observed over the front of right shoulder near the clavicular region and lower half of back (Figure 3). Singeing of body hairs was seen over lower half of back and buttock (Figure 4).

On internal examination - No bony injuries were seen. Brain was oedematous with multiple petechae. Stomach contained about 100 $\mathrm{ml}$ of reddish fluid with hemorrhagic mucosa throughout (Figure 5). Intestinal mucosa was hemorrhagic at places (Figure 6). Other visceral organs showed congestion and were unremarkable. Toxicological analysis was negative for any poisonous or inebriant substances.

*Corresponding author: Dr. Nitin Barmate, Assistant professor, Forensic Medicine, Pt. JNM Medical College, Raipur, Chhattisgarh, India-492001, Tel: 008889083686; E-mail: nitinsforensic@gmail.com

Received September 20, 2014; Accepted October 31, 2014; Published November 04, 2014

Citation: Barmate NS, Tumram NK, Singh RK, Shrigiriwar MB (2014) A Rare Case of Blast Effect by Lightening. J Forensic Res 5: 248. doi:10.4172/21577145.1000248

Copyright: (c) 2014 Barmate NS, et al. This is an open-access article distributed under the terms of the Creative Commons Attribution License, which permits unrestricted use, distribution, and reproduction in any medium, provided the original author and source are credited. 


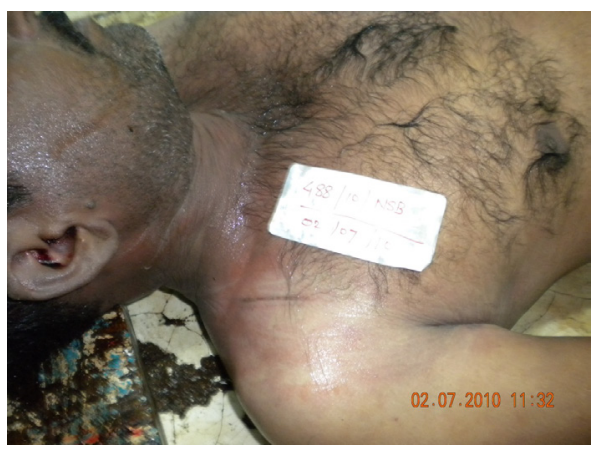

Figure 3: Epidermal burn over shoulder and clavicular region.

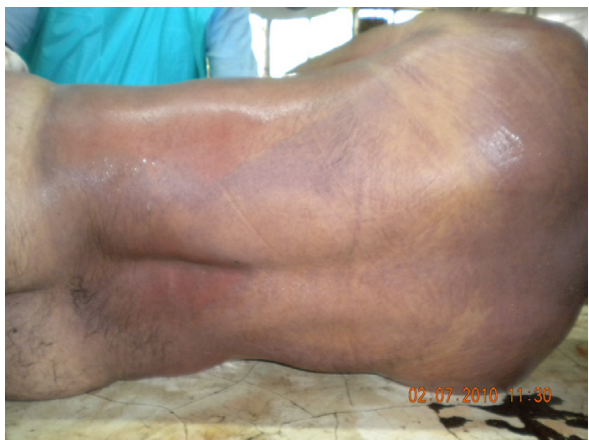

Figure 4: Singeing of body hairs.

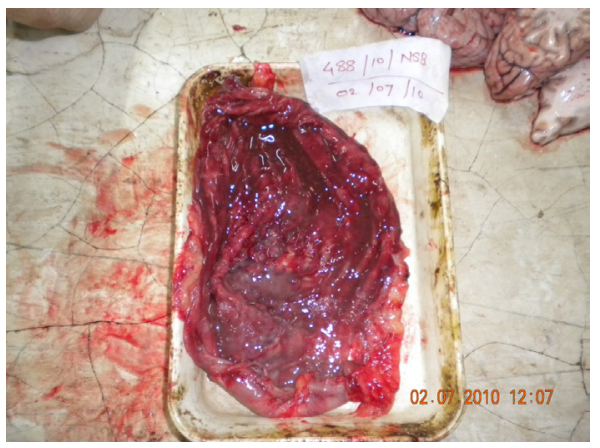

Figure 5: Mucosal and submucosal haemorrhage in stomach

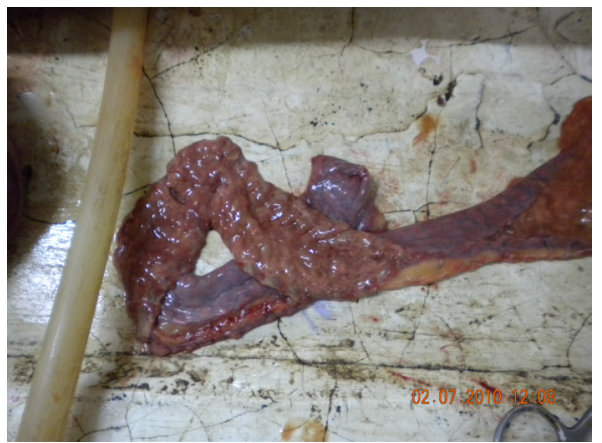

Figure 6: Submucosal haemorrhages in intestine at places.

\section{Discussion}

Lightning injuries result from electrical energy, thermal energy or the enormous blast force of thunder lightning strike. The vast majority of lightning injuries are first - and second -degree burns to the skin covering 1 and $20 \%$ of the body. Burns associated with lightning appear in several forms: feathering, linear, punctuate, thermal (from ignition of clothing), contact (from metal objects such jewellery or zippers) and flash [2].

In the present case epidermal burns wound was observed over front of right shoulder near the clavicular region and lower half of back. Singeing of body hairs was seen over lower half of back and buttock along with scorching of the shirt. Also, the victim was working in the agricultural field in a rainy day. Now about $70 \%$ of the lightning deaths occurred in the months of June, July, and August i.e. rainy season. Workrelated activities contributed to $13 \%$ of the total lightning fatalities. Of which Farming/ranching-related activities contributed most (34\%) followed by roofing (9\%), lawn care $(9 \%)$, construction $(9 \%)$, military work (6\%), barge work (6\%) and others (25\%) [3].

Shock waves created by the lightning channel causes different Injuries. During a lightning strike, in few seconds the channel temperature will be raised to about $25,000 \mathrm{~K}$ resulting, the pressure to increase to several atmospheres. The resulting rapid expansion of the air creates a shock wave which can injure a human being located in the vicinity of the lightning flash. The pressure associated with the shock wave decrease with the distance rapidly, so the shock wave can injure a human being located in the much closed vicinity of lightning flash only [4]. About $20-50 \%$ of lightning- injured victims suffer ruptured tympanic membrane in the ear. In this case, there was bleeding through both ears with otoscopic examination revel perforation of the tympanic membrane. Thus the deceased might have been in very close vicinity of the lightening strike causing the shock wave to create a blast effect on the hollow organs like ear to rupture and bleed. During a direct lightning strike to the upper part of the body, the ears can be located within the few centimetres from lightning channel. Calculation by Hill shows that the over pressure within a few centimetres of lightning channel can reach about 10-20 atm. This over pressure creates a sound impulse of about $200 \mathrm{~dB}$ which is above the pain threshold level of human hearing, which is about $120 \mathrm{~dB}$. Even if the tympanic membrane remains intact, the victims still may suffer from varying degree of permanent hearing loss and "ringing in the ear" (tinnitus) which is probably caused by the damage to hair cells and nerves in cochlea either from shock wave or by the flow of current through it [4].

Explosions cause injury through three principle mechanisms: primary blast injury, secondary injury, and tertiary injury. Primary blast injury is caused by the direct effect of a blast wave created by an explosion. Primary blast injury has three primary mechanisms. The first is spalling, which occurs when the shock wave (blast wave) transfers from a dense medium (liquid) such as water to a less dense medium (gas) such as air. It causes injury by the transfer of reflected blast wave energy through a body dense substrate (liver, muscle) into the less dense material of the gastrointestinal tract and lungs [5]. There was mucosal and submucosal hemorrhage in the stomach and intestine in the present case, which may occur as a result of spalling when the shock wave (blast wave) transfer into a less dense medium such as stomach and intestine. Also there were no localized erosions of the mucosal lining of the digestive tract which usually occur in the ulcers of the stomach or duodenum. Breakdown of the mucosal lining results in damage to blood vessels, causing bleeding. 
Citation: Barmate NS, Tumram NK, Singh RK, Shrigiriwar MB (2014) A Rare Case of Blast Effect by Lightening. J Forensic Res 5: 248. doi:10.4172/2157-7145.1000248

Page 3 of 3

\section{References}

1. Carmen A. Pfortmueller, Yang Yikun, Monika Haberkern, Erwin Wuest, Heinz Zimmermann, Aristomenis K (2012) Exadaktylosm Injuries, Sequelae, and Treatment of Lightning-Induced Injuries: 10 Years of Experience at a Swiss Trauma Center. Emergency Medicine International Volume 2012: Article ID 167698,6

2. Michael Tsokos (2006) Forensic Pathology reviews. Humana Press Inc. Totowa New Jersey 4: 9-10.
3. John S. Jensenius. A Detailed Analysis of Recent Lightning Deaths in the United States.

4. Gerard Berger. Lightning-caused accidents and injuries to humans. IX International Symposium on Lightning Protection, Foz do Iguacu, Brazil $26^{\text {th }}$ $30^{\text {th }}$ November 2007.

5. Nick Colovos. Blast Injuries. 